\title{
Menopause and the Culture of Fear: Perception Analysis
}

\author{
PhD Flor Ivett Reyes Guillén ${ }^{1 *}$, Juan Gabriel Solís Gutman², Dalaal Rosario Cruz López ${ }^{3}$ \\ ${ }^{1,2}$ Autonomous University of Chiapas, Mexico \\ ${ }^{3}$ Therapistandfacilitatorofrefreshercourses
}

*Corresponding Author: PhD Flor Ivett Reyes Guillén, Autonomous University of Chiapas, Mexico

\begin{abstract}
ThisarticlepresentstheresultsofresearchconductedinChiapas,Mexico,withtheaimofanalyzingwomen's perceptionsofmenopauseandtherelationshiptofearofdeath.Thestudyinvolvedlo0women, whocreatedtwogroupsf ortheiranalysis, oneofwomenaged40andoverandanotherfrom18to39yearsold.Itisaqualitativecuttingstudywitha multidisciplinaryapproachstartingfromthephenomenological.48\%ofwomenundertheageof39areafraidofdeath, duetotheuncertaintyitcausesthem, thesadnessofleavingunfinishedprojectsandfamilymemberssuffering. Ofwomen overtheageof40,88\%areafraidofdeath, becauseofaspectsrelatedtofamilyattachment. Severalstudieshavebeencon ductedonfearofdeath, butmostquantitativecutting; inthisarticle, inadditiontoprovidingtheanalysisofthesubjectivit iesimmersed,wespecificallyaddressthetopicofmenopause, necessaryfortheimprovementofthequalityoflifeof wom en.
\end{abstract}

Keywords: Perception, menopause, fear of death

\section{INTRODUCTION}

Menopause means the physiological or iatrogenic cessation of menstruations due to decreased ovarian function. Manifestations include hot flashes, night sweats, sleep disorders and genitourinary syndrome. Menopause is considered when she has stopped menstruating for a year, during the $40 \mathrm{~s}$ in a woman (Manual Merck, 2020).

Addressing this issue is important for health, and from different disciplines questions can be answered aimed at improving the quality of life of women at this stage and beyond. This can be explored from anthropology, psychology, biomedicine and other disciplines of the social area and humanities. The above from the understanding of menopause as a process that goes beyond the physiological, where human women have much to say; but also, a lot to ask.

In this article, we avoid setting aside what Rodman (2015) calls "the Sigh" describing the variety the emotions, sensations, beliefs, myths, related to menopause, heard from the voices of women with different religious, professional, family and ethnic constructions.

Throughout the history of humanity and from different cultures, we have decorated, clothed, and modified our bodies in various ways, with specific cultural and social purposes. Quoting Bourdieu (1994), the human body bears a symbolic value and form of physical capital; possesses distinctive power, status, and symbolic forms that are an integral part of the accumulation of resources. However, individuals or groups have a variety of opportunities to produce bodily forms that are symbolically valued and able to convert them into resources. Specifically, these body forms, body states, health and disease always allow to project the body as valued.

Today, the bodies are identified, symbolized, classified according to age, gender, race, ethnicity. Thus, in the 21st century, more than one body state and more than one representative resource can be understood. Bodies are built socially and simultaneously and even in a globalized way, giving way to diversity of situations of health and disease, leisure and work, emotions and sensations, forms of consumption, use of technology, style, risk, food, education and quality of life.

At the end of the last century and considering the implications of globalization, Burkitt (1999:2) mentions that bodies are "productive bodies" that manage to carry out activities that have interference with the same nature. At the same time, it is communicative, powerful, and thoughtful bodies, social 
relations being the ones that transform the natural and social worlds. Thus, under this cognition, in the field of health, specifically the physiological processes related to progress in the stages of human life, there is a lack in the deconstruction of the significant mobilizers of this area (Shildrick and Price, 1998:4-5). There is also the "high interference" as we mentioned, which together will make complex the deconstruction of the signifiers mentioned by Shildrick and Price.

Therefore, within anthropology a line of attention has been developed that refers to different discourses that create the body within the social, health, disease, and incarnation. From the latter Fox (1998) mentions that it is necessary to show that the incarnation is provisional. This statement directs us to the analysis of death, fear of disease and death, as elements that exhibit the vulnerability of humans.

Within the understanding of human health, the discourse of biomedicine has taken a predominant and dominant place in recent centuries; but today it requires the visibility of a complex entity that is embedded and built and deconstructed from social life. For this reason, it has begun to place bodies within the attention of other disciplines such as sociology, anthropology, psychology, communication sciences and other areas of knowledge that are required to understand the states of the human body, health, disease, existence and decadence within a globalized world.

On the other hand, perceiving is the ability to acquire knowledge of one thing, phenomenon, process, through the impressions that communicate the senses. An important aspect of studying perceptions is understanding that we are dealing with people's private experiences (Dember and Warm 1990). That is, they are undercover events, which are not likely to be observed by the observer, call yourself a psychologist, anthropologist, or anyone interacting with another. That is what we call it, armor in the face of otherness.

In this way, the concept of perception occupies the logical position of a psychological construct, a hypothetical mechanism that is used to explain certain relationships between the input, processing and exit of stimuli, as well as at a second and as a complementary process, manifest behavior.

Therefore, it requires caution, sensitivity, and patience to develop techniques that allow indirect access to this hypothetical process, through inferences made from objective data; that is, data that manages to be measured. Therefore, this article sets out the interdisciplinary way in which a study was conducted on women $(n=100)$ of various age groups in an intercultural population and in a Latin American country with development complexities.

By using perception analysis as an approach to understand health problems, and specific public health, we are compelled to contextualize. In Latin America one of the main goals pursued by public policies has been the coverage of public services, without putting the quality of these or the satisfaction of users first. Thus, the current, globalized socio-economic changes have created wide social gaps that accentuate the lack of economic and social equity, with a vastly diverse world, where necessarily the perceived environment is widely diverse. Coinciding with Arias (2006), one of the horizontal axes that affect perceptions is education, which guarantees the development of peoples; but in this region it has been underserved.

Therefore, and when talking about health, in this case perceptions about menopause, we must talk about educational deficiencies and it is in the cognitive processes that the first consequences of these deficiencies are presented. Education, thought, language and symbolism are articulating elements that guarantee the understanding of perceptual and cognitive processes. This affirmation can be made from the moment of analyzing the contributions of Blumer (1982), Piaget (1983) and Vygotsky (1934) for the understanding of the cognitive processes that detonate in man his development, growth, and development.

These contributions, complementary not exclusive, make us return to the symbolic interactionism of Blumer (1982) which is a process by which humans interact with symbols to build meanings. That is, through the symbols with which we interact, information is acquired and the generation of ideas, experiences, feelings is facilitated. This is based on three central ideas: 1) the behaviors of individuals are subject to the meaning they give to the objects of their world; 2) the meaning these things receive to the subject depends on their social interaction with other subjects in their environment and 3) the meanings depend on the subject's social experience. 
It is important to mention that several studies visualize symbolic interactionism as a positive social approach to informing analysis within the field of health and even more so in countries with geographical, social, cultural and developmental diversity (Parsons, 1982; Mummert, 1998; Castro, 2001).

The study described here was carried out in San Cristóbal de Las Casas, Chiapas, Mexico, middle city, cosmopolitan, which, empirically, and even without realizing it, works hard to achieve interculturality [understood as the interaction between cultures and the communication process before different customs, horizontally, that is, no group is above the other, promoting equality, integration and coexistence].

\section{RESEARCH METHOD}

This study is qualitative in cut, with a multidisciplinary approach starting from the phenomenological. A total of 100 women were interviewed, open population, during the last quarter of 2019 and the first quarter of 2020.

The interviews were structured and addressed two age groups of women, young women aged 18 to 39 (average age 23 years) and 40 years or older (average age 62 years); for practical purposes, the first group will be called group A and the group of 40 or more will be called group B. The questions included possible variables to answer for each age group, having variables in common that helped us to perform a comparative analysis and questions that apply only for women who were experiencing, or had experienced, the menopause process.

\section{RESULTS AND ANALYSIS OF INVESTIGATIONS}

About the mother tongue of these women, only $4 \%$ indicated to be tzotzil or tzeltal speaking. $96 \%$ have Spanish as their mother tongue. Its religious affiliation is Catholicism by $92 \%$; $5 \%$ are Christians, $1 \%$ are Pentecost and $2 \%$ without religion.

In terms of the level of education, $4 \%$ with postgraduate; $8 \%$ primary education; $10 \%$ secondary education; $1 \%$ out of school and $77 \%$ with university level. It is important to mention that it is a high percentage of women who have passed university education, even more so when we consider that Chiapas has poverty as one of the main factors that are linked to the educational lag. According to the National Institute for Adult Education (INEA) Chiapas is in the first places of educational lag in the country. In this state, more than $50 \%$ of the population over the age of 15 does not have secondary studies (1, 900, 000 inhabitants).

Intermsofoccupancy, $16 \%$ arehousewives, $16 \%$ merchants, $8 \%$ teachers, $6 \%$ retirees, $8 \%$ administrativestaff ;4\%employedinestablishedshops. Theremainingpercentage, $58 \%$,isstudents.

Knowledge about menopause and definition. Within the study, $4 \%$ of the total interviewees do not know what menopause is and therefore do not define it. $96 \%$ if they know what it is and define it as "it is the time when menstruation goes away" and add, in some cases, the presence of hot flashes, irritability and hormonal decompensation.

Paradoxically, regarding the identification of symptoms, $14 \%$ say they do not know the symptoms; the remaining percentage commonly identifies the lack of menstruation, hot flashes, hormonal changes, and these generate changing moods.

The results in this section show that the study population has knowledge about the most common signs and symptoms of menopause, not so with a concept that places it within its daily life, much less because it has obtained it from valid sources. This reality has no significant relation to age or the level of schooling of those interviewed.

Perception about the stage of life as you go through menopause. Only $6 \%$ think it is a good stage because they stop menstruating. The remaining percentage (94\%) they perceive menopause as an extremely complicated stage because there are changes that affect physically and emotionally and even perceive that women are misunderstood at this stage and become depressed.

Hormonalchangesaffectemotionalstability, whichgeneratessituationsofmoodinessandhypersensitivityth atmanifestnotonlyinpremenopausaltimesormenopause,butinallthosemomentsinthelifeofthewomanwhe nthesehormonalchangesareabruptlygenerated,suchaspregnancies, thefirstmenstruations. Thesehormonal alterationsarealsoinsomecasestriggersofpathologiessuchasanxiety,depression,internalconflictsofidentit yandself-esteem. 
Fear of death, Tanatophobia. $48 \%$ of women in Group A are afraid of death, due to the uncertainty it causes them, the sadness of leaving their projects unfinished and their relatives suffering. The remaining percentage (52\%) he is not afraid of death because they consider it a natural process.

Of group B ( $\geq 40$ years), $88 \%$ are afraid of death, for aspects related to family attachment. The $12 \%$ who are not afraid of death affirm this reality with their religious faith.

The name by which he is known to fear of dying is Tanatophobia; butit is not always aphobia. Almost every one is afraid of death; some people are more afraid of him tan others; the truth is that some degree off earis healthy because it makes you not expose yourself to dangers unnecessarily.

Within the study group, women over the age of 40 have a higher percentage fear of death and at the same time fear of aging, a phenomenon that usually occurs after age 30.

Fear of old age, Gerontophobia. $68 \%$ of women in group A are not afraid of old age, emphasizing that this is a natural stage in everyone's life and want to reach that stage to see their achievements. The remaining percentage belongs to women who are afraid of old age because they feel they will be weaker at that stage.

$15 \%$ of women in group B (40 years old) are not afraid of old age because it generates them to reach that age and enjoy seeing the growth of their children. The remaining percentage (85\%), old age fears because there are many limitations and diseases, focusing their fear on health deficits and increasing dependence on others.

\section{CONClusion}

There are a large number of authors who contributed, at different points in history, elements that allow us to observe the transition of conceptualization, understanding and fear of death (Fiefel ,1959; Pandey and Templer, 1972; Hoelter, 1979; Ramos, 1982; Collet and Lester, 1984; Thomas-Saturday; Fuerer and Walker, 2008; Anton, 2015; Nieto, 2015, among others).

The above corresponds to some of the studies within the area of Tanatology; however, we can also talk about fear, from sociology and anthropology, as a social construct. Fear represents one of the basic emotions of the human being and is associated with anguish, anxiety, panic, which are part, so to speak, of forms of expression of fear.

Fears are built from experiences within objective and subjective conditions. The objective manifestations, in the case at hand, the menopause associated with old age and this to death, form social representations that underpin the ways of perceiving, imagining and relating the individual to his environment, which can, at a time, be associated with situations of danger. These representations, imaginary of evil situations, are not fictional, illusions or fantasies around menopause-old-death; but part of a pre-established social tension, in relation to women, their social roles, their image in relation to beauty, their status in relation to their age.

The triad menopause-old-death is framed in a series of stereotypes as forms of discrimination, with verbal actions [derogatory expressions such as sarcasm and insults] and nonverbal [abandonment, relegation, conditioning]. This involves disqualifying and segregating women with marked boundaries between one age group and another: and they obviously manifest social differences. There is no doubt that these stereotypes have a strong subjective burden, representations and imaginary generally unfounded; but they are the components that will generate a condition of fear to go through this process and be labeled by the next society (with which they coexist day by day) and the distal (through what is published in mass media).

According to Lester (1967), age affects attitudes about fear of death dynamically until mental development has been completed in an individual; it is from this moment that personality factors and life experiences are given greater importance as determinants.

For their part Feifel and Brascomb (1973) consider that death is essentially the expression of the fear of death. From this reasoning, the Management of Terror, set out by Pyszcnski et al (1999).

Specifically, the literature on fear of death in adults' states that they are less afraid of death than younger people (Templer et al 1971; Kallish and Johnson, 1972; Marshall, 1975; Bengston et al, 1977; Kastenbaum, 2000). In the research we presented in this article, the opposite was found with 
high percentages, speaking in addition to the 21 st century, year $2020.80 \%$ of women interviewed over the age of 40 are afraid of death; while in young women only $48 \%$. In both cases fear is generated by attachment to the family mainly. Young women add another reason, to leave unfinished projects.

However, in studies that claim less fear of death in adults, variables such as poor quality of life, loss of health, widowhood, are inversely related to this fear. And indeed, in our study, these same variables, in both age groups, are associated with fear of old age, but not death. The main fear of old age is the loss of autonomy.

It is then that we are approaching to argue that, young people or adults, in this twenty-first century, year 2020, in San Cristóbal de Las Casas, Chiapas, Mexico, are fearing old age, for the loss of autonomy; and death by family attachment. This fear is greater as age progresses. This claim is contrary to Kastenbaum, who suggests that death anxiety is directly proportional to people's chronological age.

The explanation, for this contradiction, may be given by what, in 1966 Munnichs explained, the decrease in the anxiety of death could result from the denial initiated by the imminent reality of dying, or the impossibility of preparing to face it. Also, Templer et al, 1971; Vianey in 1984; Vargo and Blak in 1984 and Wagner and Lorion in 1984 did not find a significant decrease in death anxiety with age.

We know that these studies mentioned were mostly quantitative cutting; however, variables such as anxiety or fear cannot be talked about, let alone death, without taking into account the results of qualitative studies that reflect subjectivity immersed in this reality of study.

\section{REFERENCES}

[1] Manual Merck (2020). Merck Sharp \& Dohme Corp., una subsidiaria de Merck \& Co., Inc., Kenilworth, NJ., USA. https://www.msdmanuals.com/es-mx/professional/ginecolog\%C3\%ADa-y-obste tricia/menopausia/menopausia

[2] Rodman GB (2015). Why Cultural Studies?. Wuley Blackwell Oxford, UK 206 pp.

[3] Bourdieu, P. (1984). Distinction, A Social Critique of the Judgement of Taste. London: Routledge and Kegan Paul.

[4] Burkitt, I. (1999). Bodies of Thought: Embodiment, Identity and Modernity. London: Sage Publications, Ltd.

[5] Shildrick, M. and Price, J. (1998). Introduction: Vital signs: texts, bodies and biomedicine, in M. Shildrick and J. Price (eds) Feminist Reconfigurations of the Bio/logical Bbody. Edinburgh: Edinburgh University Press, pp. 1-17.

[6] Fox, N. (1998). The promise of postmodernism for the sociology of health and medicine, in G. Scambler and P. Higgs (eds) Modernity, Medicine and Health: Medical Sociology Towards 2000. London: Routledge, pp. 29-45.

[7] Dember, W.N. y Warm, J.S. (1990). Cap. 5 de Psicología de la percepción. Madrid: Alianza.

[8] Arias CCA (2006). Enfoques teóricos sobre la percepción que tienen las personas. Hoiz. Pedagog. Volúmen 8 No. 1 P 9-22

[9] Blumer, H (1982). El interaccionismo simbólico, la perspectiva y método. Barcelona, España.

[10] Piaget, J. (1983). Esquemas de acción y aprendizaje del lenguaje. En Centre Royamount Pour une Science de l'homme. Teorías del lenguaje, teorías del aprendizaje: el debate entre Jean Piaget y Noam Chomsky. Barcelona: Editorial Crítica.

[11] Vigotsky, L. (1934). Pensamiento y lenguaje. Buenos Aires, Fausto.

[12] Parsons, T (1982). Estructura social y procesos dinámicos. El caso de la práctica médica. En ídem, El sistema Social (pp.439-449). Madrid. Alianza Universidad.

[13] Mummert, G (1998). Repensar la salud-enfermedad-atención en México desde las Ciencias Sociales. Relaciones (74). Vol. XIX. El Colegio de Michoacán. México.

[14] Castro, R (2001). Sociología médica en México: el último cuarto de siglo. Revista Mexicana de Sociología. (No. 3). p. 271-293

[15] INEA (2020). Instituto nacional para la educación de los adultos. http://www.inea.gob.mx/index.php

[16] Feifel, H. (1959). The meaning of death. McGraw---Hill. New York

[17] Pandey,R.E. and Templer, D.I. (1972).: Use of the death Anxiety Scale in an inter-racial setting. Omega. 3: 127-130. 
[18] Hoelter, J. W. (1979). Multidimensional treatment of fear of death. Journal of Consulting and Clinical Psychology, 47,996-999.

[19] Ramos, F. R. (1982). Personalidad,depresión y muerte. (Tesis doctoral inédita). Departamento de Personalidad, Evaluación, y trabamiento psicológico. Facultad de Psicología. Madrid: Universidad Complutense de Madrid.

[20] Collet, L., y Lester, D. (1969). The fear of death and the fear of dying. Journal of Psychology, 7,179---181.

[21] Tomás- Sábado j, Limonero, Abdel-Khalek AM (2007). Spanish adaptation of the Collett-Lester fear of death scale. Death Stud 2007; 31:249-60.

[22] Furer, P., y Walker, J. R. (2008). Death anxiety: A cognitive behavioral approach. Journal of Cognitive Psychotherapy, 22,167-182.

[23] Anton Hurtado, Fina (2015). Antropología del miedo. Methaodos revista de ciencias sociales. 3(2), 262 275

[24] Nieto Munuera, J. (2015). El miedo en la sociedad actual. Universidad de Murcia.https://webs.um. es/jalozate/lozanoteruel/ColaboracionesAmigas/Presentaciones/Elmiedoenlasociedadactual.pdf

[25] Lester, D. (1967). Experimental and correlation studies of the fear of death. Psychology Bulletin, 67, $27-$ 36.

[26] Feifel, H., y Brascomb, A. B. (1973). Who's afraid of death? Journal of Abnormal Psychology, 81, 282288.

[27] Pyszczynski, T., Greenberg, J., y Solomon, S. (1999). A dual-process model of defense against conscious and unconscious death-related thoughts: An extension of terror management theory. Psychological Review, 106, 835-845.

[28] Templer, D. I., Ruff, C. F., y Franks, C. M. (1971). Death Anxiety: Age, sex, and parental resemblance in diverse populations. Developmental Psychology, 4, 108.

[29] Kalish, R. A., y Johnson, A. I. (1972): Values similarities and differences in three generations of women. Journal of Marriage and Family, 34, 49-54.

[30] Marshall, V. W. (1975). Socialization for impending death in a retirement village. The American Journal of Sociology, 80(5), 1122-1144.

[31] Bengston, V. L., Cuellar, J. B., y Ragan, P. K. (1977). Stratum contrasts and similarities in attitudes towards death. Journal of Gerontology,32, 76-88.

[32] Kastenbaum, R., y Aisenberg, R. (1972). The Psychology of Death. New York: Norton.

[33] Vianey, L. L. (1984). Concerns about death among severely ill people. In F. R. Epting y R. A. Neimeyer (Eds.), Personal meanings of death (pp. 143-158). Washington, DC: Hemisphere.

[34] Vargo, M. E., y Black, F. W. (1984). Attribution of control and the fear of death among first year medical students. Journal of Clinical Psychology, 40, 1525-1528.

[35] Wagner, K. D., y Lorion, R. P. (1984). Correlates of death anxiety in elderly persons. Journal of Clinical Psychology, 40,1235-1241.

Citation: PhD Flor Ivett Reyes Guillén, et.al. "Menopause and the Culture of Fear: Perception Analysis" International Journal of Research in Sociology and Anthropology (IJRSA), vol 6, no. 2, 2020, pp. 01-06. doi: http://dx.doi.org/10.20431/2454-867 7.0602001.

Copyright: (C) 2020 Authors. This is an open-access article distributed under the terms of the Creative Commons Attribution License, which permits unrestricted use, distribution, and reproduction in any medium, provided the original author and source are credited. 